\title{
REVIEW \\ latrogenic urological triggers of autonomic dysreflexia: a systematic review
}

\author{
N Liu ${ }^{1,2}$, M Zhou $^{1}$, F Biering-Sørensen ${ }^{3}$ and AV Krassioukov ${ }^{2,4,5}$
}

\begin{abstract}
Study design: This is a systematic review.
Objective: The objective of this study was to review the literature on iatrogenic urological triggers of autonomic dysreflexia (AD).

Setting: This study was conducted in an international setting.

Methods: A systematic review was conducted from PubMed search using AD/ autonomic hyperreflexia and spinal cord injury (SCI). Studies selected for review involved iatrogenic urological triggers of $A D$ in individuals with $S C l$, including original articles, previous practice guidelines, case reports and literature reviews. Studies that did not report AD or blood pressure (BP) assessments during urological procedures were excluded.
\end{abstract}

Results: Forty studies were included for analysis and categorized into four groups: (1) urodynamics and cystometry; (2) cystoscopy and transurethral litholapaxy; (3) extracorporeal shock-wave lithotripsy (ESWL); and (4) other procedures. During urodynamics, the incidence of $A D$ ranged from $36.7 \%$ to $77.8 \%$. The symptomatic rate ranged from $50 \%$ to $65 \%$, with $A D$ symptoms seen predominantly in cervical SCl patients. The studies imply no consensus regarding the relationship between $A D$, neurogenic detrusor overactivity and detrusor sphincter dyssynergia. Without anesthesia, the majority of individuals develop AD during cystoscopy, transurethral litholapaxy and ESWL. The effectiveness of different anesthesia methods relies on blocking the nociceptive signals from the lower urinary tract (LUT) below the level of the neurological lesion. Other iatrogenic urological triggers were commonly associated with bladder filling.

Conclusion: The LUT triggers of episodes of AD are often associated with iatrogenic urological procedures. AD was more prevalent in cervical SCl than in thoracic SCl. To detect this potential life-threatening complication following cervical and high thoracic SCl, routine BP monitoring during urological procedures is highly recommended.

Spinal Cord (2015) 53, 500-509; doi:10.1038/sc.2015.39; published online 24 March 2015

\section{INTRODUCTION}

Autonomic dysreflexia $(\mathrm{AD})$ is a potential life-threatening condition, and it is considered a clinical emergency ${ }^{1,2}$ characterized by a constellation of signs and/or symptoms in response to a noxious or non-noxious stimuli originating below the level of the neurological lesion in individuals with spinal cord lesions at or above T6. ${ }^{3,4}$ During $\mathrm{AD}$, systolic arterial blood pressure (BP) may increase to $300 \mathrm{~mm} \mathrm{Hg}$ and may, without immediate treatment, result in seizure, intracranial hemorrhage, myocardial infarction or death. ${ }^{5-11}$

A sudden and massive increase in systolic and diastolic BP (SBP and $\mathrm{DBP}$, respectively) in response to noxious or non-noxious stimuli below the level of injury is a defining criterion for AD. ${ }^{12}$ Bradycardia frequently accompanies episodes of $\mathrm{AD}$ and typically occurs as a result of baroreceptor-mediated increase in vagal activity above the neurological level owing to increased arterial BP; however, tachycardia is also documented in individuals suffering from AD. ${ }^{13}$ During an episode of $\mathrm{AD}$, individuals frequently experience the following signs and symptoms: pounding headache, goose bumps (cutis anserine), anxiety, flushing, sweating above the neurological level of lesion, malaise and nausea. ${ }^{14}$ Despite this typical presentation of $\mathrm{AD}$ with objective signs and subjective complaints, a variety of studies ${ }^{15-19}$ have recognized a condition referred to as 'silent $\mathrm{AD}$ ', which includes a significant increase in BP in the absence of other objective signs and subjective complaints.

The International Standards for Neurological Classification of Spinal Cord Injury evaluates sensation and voluntary motor strength, ignoring the role of the autonomic nervous system (ANS). To address impairments to the ANS, the International Standards to Document Remaining Autonomic Function after Spinal Cord Injury (ISAFSCI) was developed. ${ }^{3,4}$ One of its more extensive topics was $\mathrm{AD}$, which is defined as an increase in SBP> $20 \mathrm{~mm} \mathrm{Hg}$ above baseline, with or without headache, flushing, piloerection, stuffy nose, sweating above the level of the neurological lesion, vasoconstriction below the level of the lesion or dysrhythmias.

In most cases (75-90\%), ${ }^{2,20,21} \mathrm{AD}$ is triggered by events located in the lower urinary tract (LUT). Triggering of AD in the LUT happens in the course of living with a neurogenic bladder, such as indwelling catheter obstruction, malposition of the catheter tip, overfilling of the drainage bag, allowing the bladder to excessively distend between intermittent catheterizations and LUT infection. The cause is

${ }^{1}$ Department of Rehabilitation Medicine, Peking University Third Hospital, Beijing, China; ${ }^{2}$ International Collaboration on Repair Discoveries (ICORD), Department of Medicine, University of British Columbia, Vancouver, British Columbia, Canada; ${ }^{3}$ Department for Spinal Cord Injuries, Glostrup Hospital, University of Copenhagen, Copenhagen, Denmark; ${ }^{4}$ Division of Physical Medicine and Rehabilitation, University of British Columbia, Vancouver, British Columbia, Canada and ${ }^{5}$ GF Strong Rehabilitation Centre, Vancouver Coastal Health, Vancouver, British Columbia, Canada

Correspondence: Dr AV Krassioukov, ICORD-BSCC, University of British Columbia, 818 West 10th Avenue, Vancouver, British Columbia, Canada V5Z 1M9.

E-mail: krassioukov@icord.org

Received 22 July 2014; revised 15 December 2014; accepted 12 January 2015; published online 24 March 2015 
sometimes iatrogenic if, for example, the $\mathrm{AD}$ occurs during cystoscopy, cystometry, cystography, electroejaculation, penile vibration, ${ }^{15}$ urodynamic evaluation and extracorporeal shock-wave lithotripsy $(E S W L){ }^{12}$ As sexual procedures related to $\mathrm{AD}$ were already reviewed, ${ }^{22}$ the aim of this study was to review the literature on the iatrogenic urological triggers of $\mathrm{AD}$.

\section{MATERIALS AND METHODS}

A systematic literature review from PubMed was conducted on all English-language studies that provided scientific evidence for iatrogenic urological triggers of AD following spinal cord injury (SCI). The keywords used during the search were population search terms that included 'paraplegia', 'tetraplegia', 'quadriplegia', 'spinal cord inj*', 'spinal cord $\operatorname{dys}^{\star}$ (function)', 'spinal cord dis ${ }^{\star}$ ' and 'spinal cord lesion', as well as 'autonomic dysreflexia' or 'autonomic hyperreflexia'. Studies published between 1956 and 2014 were included into the search. The studies were assessed by two independent reviewers on the basis of each study abstract, which had to mention urological procedures and resultant $\mathrm{AD}$ or $\mathrm{BP}$ elevation. The selected studies included original articles, practice guidelines, case reports and literature reviews pertaining to iatrogenic urological triggers of $\mathrm{AD}$. Studies with no data on $\mathrm{AD}$ or changes in $\mathrm{BP}$ during urological assessments were excluded. When the abstracts indicated relevance, authors retrieved the full-text articles, reviewed them and reached a consensus opinion.

\section{RESULTS}

The search yielded 691 articles. Articles that did not mention a urological procedure and $\mathrm{AD}$ were removed from the sample, because they did not include iatrogenic urological triggers of $\mathrm{AD}$. This resulted in a total of 40 articles from which data were extracted for the current review. The included articles were divided into four groups according to the urological procedure: (1) urodynamics and cystometry $(n=21)$; (2) cystoscopy and transurethral litholapaxy $(n=12)$; (3) ESWL $(n=6)$; and (4) other procedures $(n=2)$. The 'other procedures' were voiding cystourethrography, loopography and micturition trial. One study involved both urodynamic investigation and cystoscopy.
Incidence of $\mathrm{AD}$ during iatrogenic urological procedures

The incidence of AD during urodynamics, cystoscopy and ESWL is shown in Table 1 . The incidence of $\mathrm{AD}$ during urodynamics varied $^{15-17,21,23-26}$ ranging from $36.7 \%$ to $77.8 \%$. This variation was influenced primarily by the neurological level and severity of the SCI. One study ${ }^{27}$ reported the incidences for individuals with American Spinal Injury Association Impairment Scale (AIS) A and B to be $15.9 \%$ and $21.4 \%$, respectively. However, this study involved individuals with SCI from $\mathrm{C} 4$ to $\mathrm{T} 12$. As the majority of $\mathrm{AD}$ would occur in SCI individuals injured at or above $\mathrm{T} 6$, the lower $\mathrm{AD}$ incidence in $\mathrm{T} 7$ to T12 group would lead to the lower overall incidence, that is, underestimating the incidence rate. It is traditionally expected that essentially all $\mathrm{AD}$ cases occur in individuals with injury at or above the T6 spinal. However, a few cases reported in the literature showed that episodes of $\mathrm{AD}$ could occur with SCI as low as L1. ${ }^{24}$ It has to be understood that in all of these studies only the level of motor and sensory injuries was evaluated, without comment on the level of autonomic injury. As the more recent literature evidence suggests, the level of motor/sensory injury could differ with autonomic injury within the spinal cord. ${ }^{28}$ Unfortunately, this same study did not report the incidence above T6 separately. Alderson et al. ${ }^{29}$ revealed that 21 out of the $45(47 \%)$ individuals with SCI developed AD during transurethral surgery; however, the authors did not mention the percentage of individuals injured above T6. In comparison, Snow et al. ${ }^{30}$ reported a $70 \%$ incidence of $\mathrm{AD}$ during cystoscopy in individuals injured at or above T6 and no incidence for individuals with neurological lesions below T7. The incidence of AD during ESWL seems to be lower than that during urodynamics and cystoscopy, as a single study performed by Stowe et al. ${ }^{31}$ reported that 9 out of the 40 (23\%) individuals injured at or above T8 developed AD during the ESWL procedure.

\section{Urodynamics and cystometry}

Urodynamic investigation is considered the most common iatrogenic trigger of $\mathrm{AD}$. Numerous investigators (Table 2) use urodynamics as a screening tool for AD. Giannantoni et al. ${ }^{15}$ revealed that all patients with a lesion above T6 had significant BP elevation during

Table 1 The incidence of autonomic dysreflexia during iatrogenic urological procedures

\begin{tabular}{|c|c|c|c|c|c|c|}
\hline \multirow[t]{2}{*}{ First author, year (reference), country } & \multirow[t]{2}{*}{ Overall (above T6) } & \multicolumn{3}{|c|}{ Level of injury } & \multicolumn{2}{|c|}{ Completeness of injury } \\
\hline & & Cervical & Thoracic at or above T6 & Below T6 & Complete & Incomplete \\
\hline \multicolumn{7}{|l|}{ Urodynamics } \\
\hline Lindan, $1980,{ }^{21}$ USA & $48 \%(103 / 213)$ & $60 \%(86 / 143)$ & $20 \%(17 / 87)$ & NA & NA & NA \\
\hline Linsenmeyer, $1996,{ }^{16}$ USA & $78 \%(35 / 45)$ & $79 \%(31 / 39)$ & $67 \%(4 / 6)$ & NA & NA & NA \\
\hline Curt, 1997, ${ }^{17}$ Switzerland & $42 \%(13 / 31)$ & $59 \%(13 / 22)$ & $0 \%(0 / 9)$ & NA & $50 \%(10 / 20)$ & $27 \%(3 / 11)$ \\
\hline Chancellor, $1998,{ }^{23}$ USA & $57 \%(16 / 28)$ & NA & NA & NA & NA & NA \\
\hline Giannantoni, $1998,{ }^{15}$ Italy & $42 \%(20 / 48)$ & $54 \%(13 / 24)$ & $29 \%(7 / 24)$ & NA & $44 \%(4 / 9)$ & $41 \%(16 / 39)$ \\
\hline Huang, 2011, ${ }^{24}$ Taiwan & $43 \%(40 / 94)$ & $45 \%(38 / 85)$ & $22 \%(2 / 9)$ & $15 \%(4 / 26)$ & $40 \%(19 / 48)$ & $35 \%(25 / 72)$ \\
\hline Huang, 2013,25 Taiwan & $42 \%(42 / 101)$ & NA & NA & NA & NA & NA \\
\hline Sayılır, 2013,26 Turkey & $56 \%(50 / 90)$ & $56 \%(50 / 90)$ & NA & NA & NA & NA \\
\hline \multicolumn{7}{|l|}{ Cystoscopy } \\
\hline Alderson, 1976,29 UK & NA & $79 \%(19 / 24)$ & $10 \%(2 / 21)$ & NA & NA & \\
\hline Snow, 1978,30 USA & $70 \%(40 / 57)$ & $80 \%(33 / 41)$ & $44 \%(7 / 16)$ & $0 \%(0 / 45)$ & NA & NA \\
\hline \multicolumn{7}{|l|}{ ESWL } \\
\hline Stowe, $1989,{ }^{31}$ USA & $23 \%(9 / 40)$ & $21 \%(6 / 28)$ & $25 \%(3 / 12)^{a}$ & $0 \%(0 / 12)$ & NA & NA \\
\hline
\end{tabular}

Abbreviations: ESWL, extracorporeal shock-wave lithotripsy; NA, not available.

aThoracic at or above T8. 
Table 2 Urodynamics and cystometry

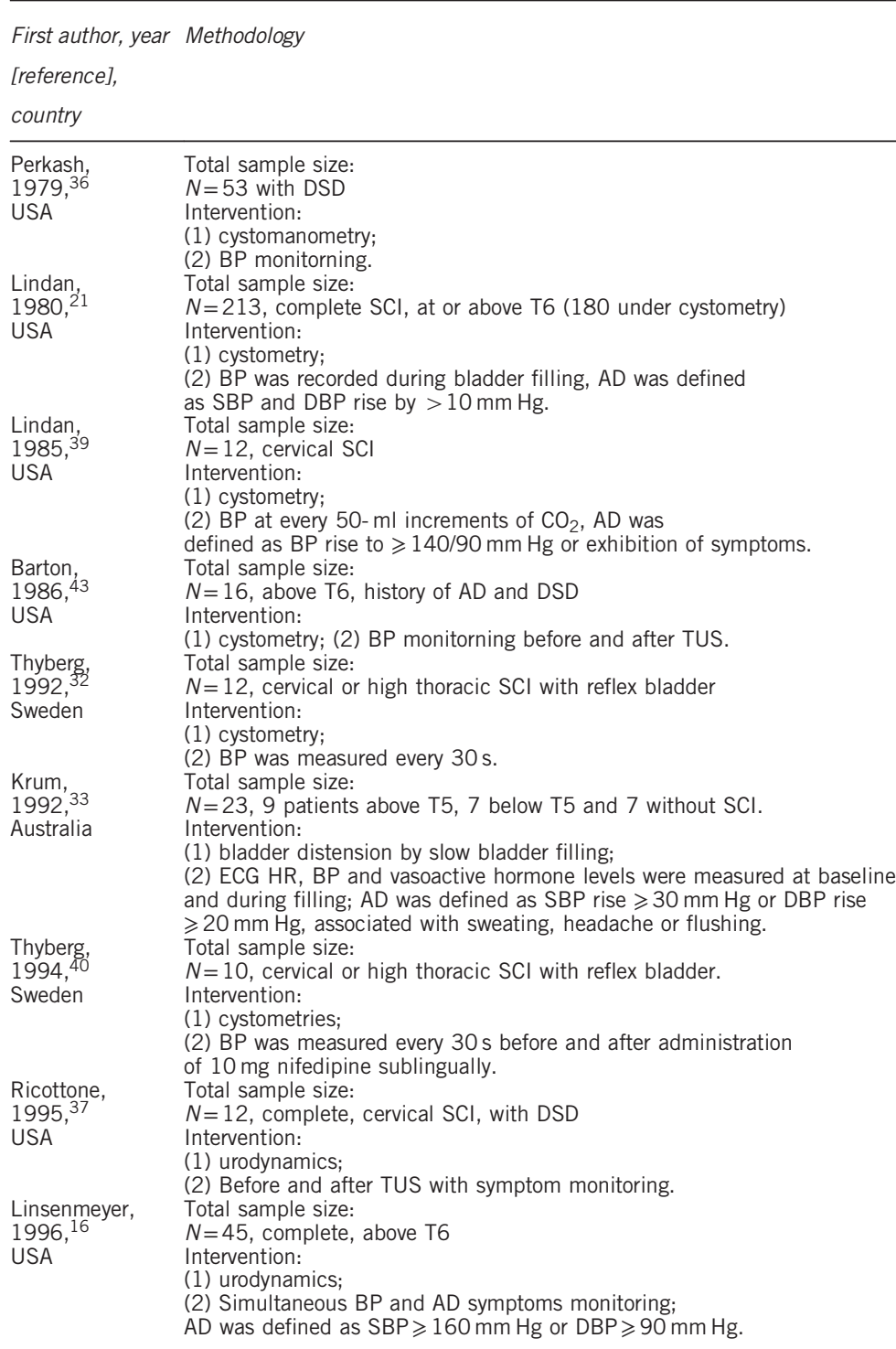

Results

(1) High correlation among BP increase, level of injury and severity of DSD

(2) In tetraplegia, SBP increases $\geqslant 40 \mathrm{~mm} \mathrm{Hg}$ and DBP increases $\geqslant 20$

$\mathrm{mm} \mathrm{Hg}$ were significant to suspect DSD.

(3) In paraplegia below T5, SBP increases $\geqslant 20 \mathrm{~mm} \mathrm{Hg}$ and DBP increases

$\geqslant 10 \mathrm{~mm} \mathrm{Hg}$ were significant to suspect DSD.

(1) $48 \%$ of the patients at risk developed AD.

(2) More prevalent in patients with cervical lesions.

(3) Majority exhibited signs and symptoms of AD by 6 months postinjury, and $92 \%$ by the end of the first year.

(1) Regular daily dosage with phenoxybenzamine or nifedipine will not prevent $A D$

(2) Nifedipine, $10 \mathrm{mg}$ orally, is indicated for the treatment of acute AD.

(3) Nifedipine, $10 \mathrm{mg}$ sublingually or orally, can be given prophylactically to abort AD.

(1) Before TUS, 12 patients (75\%) had evidence of AD.

(2) After TUS, significant decrease in BP. Frequency and magnitude of AD can be diminished significantly by TUS.

(1) SBP (20-60 mm Hg) and DBP (15-55 mm Hg) elevation in each cystometry.

(2) The maximum BP always occurred during the emptying phase and in close relation to the peak Pdet.

(1) SBP increased significantly by $56 \mathrm{~mm} \mathrm{Hg}$ (48\%) and DBP increased by $22 \mathrm{~mm} \mathrm{Hg}(47 \%)$ in high spinal lesion; the rise in BP was associated with a significant fall in HR.

(2) SBP, DBP and HR did not change significantly in low spinal lesion or normal control group.

(1) Before administration, SBP varied from $113 \mathrm{~mm} \mathrm{Hg}$ to $147 \mathrm{~mm} \mathrm{Hg}$, and DBP varied from 76 to $110 \mathrm{~mm} \mathrm{Hg}$ during cystometry.

(2) After administration, SBP varied from 99 to $118 \mathrm{~mm} \mathrm{Hg}$, and DBP

varied from 67 to $83 \mathrm{~mm} \mathrm{Hg}$ during cystometry.

(3) Nifedipine has a prophylactic effect.

(1) Before TUS, all demonstrate DSD and associated AD symptom with bladder filling.

(2) Following initial TUS, nine experienced cessation of AD.

(3) Most required repeat procedures for long-term resolution.

(1) 35 patients had AD (77.8\%).

(2) 15 patients had silent AD (43\%).

(3) Before voiding, no difference in SBP between with and without

hypertension ( 117 vs $110 \mathrm{~mm} \mathrm{Hg}, P=0.28$ ).

(4) During UDC, SBP was significantly higher in the hypertensive group

$(169 \mathrm{~mm} \mathrm{Hg})$ vs the normotensive group $(131 \mathrm{~mm} \mathrm{Hg})(P<0.000 \mathrm{l})$

(5) No difference in BP between symptomatic and silent AD before and during UDC.

(6) No correlation of AD with duration of injury, bladder management, maximum voiding pressures or bladder capacity.

(7) No correlation of symptoms with duration of injury, maximum voiding pressures or bladder capacity.

(1) Before TUS, SBP rise was $32.4 \pm 16.3 \mathrm{~mm} \mathrm{Hg}$, and DBP rise was

$14.3 \pm 9.3 \mathrm{~mm} \mathrm{Hg}$.

(2) Following TUS, SBP rise was $15.5 \pm 0.1 \mathrm{~mm} \mathrm{Hg}$, and DBP rise was

$7.3 \pm 8.6 \mathrm{~mm} \mathrm{Hg}(P=0.001)$.

(3) High correlation exists between the magnitude of BP response, level of injury and severity of DSD.

(1) In nine with UDC, MAP increased progressively during bladder contraction until reaching MBP and continued elevation during voiding.

(2) In two with DSD, maximal MAP occurred at or before MBP.

(1) $13(59 \%$ ) (10 complete, 3 incomplete) of 22 tetraplegic patients and 0 paraplegic patient presented signs of $A D$.

(2) $8(62 \%)$ of 13 patients complained of symptoms of $A D$

(3) During urodynamics, SBP increased from $115 \pm 17$ to $155 \pm 32 \mathrm{~mm}$ -

$\mathrm{Hg}$, and DBP increased from $64 \pm 13$ to $82 \pm 16 \mathrm{~mm} \mathrm{Hg}(P<0.001) ; \mathrm{HR}$ reduced from $59 \pm 6$ to $53 \pm 10$ b.p.m. $(P<0.01)$.

(4) Signs of AD were induced by bladder distension and were related mainly to hyperreflexive bladder contractions and DSD. 
Table 2 (Continued)

First author, year Methodology

Results

[reference],

country

\begin{tabular}{lll}
\hline Chancellor, & Total sample size: & (1) 16 (57\%) of 28 with lesions above T7 diagnosed as AD. \\
1998,23 & $N=32$, suprasacral SCl with detrusor hyperreflexia & (2) $72 \%$ had a positive ice-water test. \\
USA & Intervention: &
\end{tabular}

Intervention:

(2) $72 \%$ had a positive ice-water test.

(1) urodynamics and ice-water test.

(2) AD was defined as SBP increase $\geqslant 50 \mathrm{~mm} \mathrm{Hg}$ within $3 \mathrm{~min}$ of ice-water

instillation

Giannantoni, Total sample size:

1998, ${ }^{15} \quad \quad N=48,23$ cervical, 25 thoracic above T6. 39 AIS A, 9 incomplete SCI.

Italy Intervention:

(1) $20(41.6 \%)$ showed AD during urodynamics.

Intervention:

(1) urodynamics; (2) SBP, DBP and PR were recorded before filling CMG and monitored every
2 min and at the beginning of each UDC. AD was defined as

$\mathrm{BP} \geqslant 100 \mathrm{~mm} \mathrm{Hg}$.

Lee, $\quad$ Total sample size:

2003, $41 \quad N=8$, male, cervical SCl

Korea Intervention:

$\begin{array}{ll}\text { (1) cystometry with and without DPN stimulation; } & \text { (2) SBP and DBP increased as Pdet increased in all cases. } \\ \text { (2) BP and Pdet monitoring; AD was defined as SBP increase } \geqslant 40 \mathrm{~mm} \mathrm{Hg} \text {. } & \text { (3) SBP and DBP during the first contraction decreased to } 131.4 \pm 9.9 \text { and }\end{array}$

A patients, SBP incr

(3) $13(65 \%)$ of 20 showed AD symptoms.

(4) AD was more frequent in cervical patients.

(5) No correlation of AD with sex ratio, age, disease duration, completeness of lesion, incidence of NDO and DSD.

(1) SBP increased from $122.7 \pm 13.2$ to $149.1 \pm 15.2 \mathrm{~mm} \mathrm{Hg}$, and DBP

increased from $73.1 \pm 5.3$ to $89.7 \pm 8.9 \mathrm{~mm} \mathrm{Hg}$ during the first contraction $(P<0.01)$

(2) SBP and DBP increased as Pdet increased in all cases.

a d

$(P<0.01)$.

(4) DPN stimulation decreased the increased BP in AD.

(1) UDC usually combined AD in patients above T6

(2) $20(15.9 \%)$ with AIS A and $6(21.4 \%)$ with AIS B documented AD.

2008, $27 \quad$ N=154, 126 AIS A, 28 AIS B

Greece Intervention:

(1) urodynamics and retrograde cystography;

(2) AD documented either during urodynamics or by episodes needing medical intervention.

$\begin{array}{ll}\text { Huang, } & \text { Total sample size: } \\ 2011,24 & N=120, \text { suprasacral SCI, } 94 \text { above T6, } 48 \text { complete. }\end{array}$

Taiwan

Intervention:

(1) urodynamics with cystourethrometry and concentric needle electrodes;

(2) BP and PR were measured before the examination, during bladder filling and after the examination. AD was defined as an SBP increase of $\geqslant 20 \mathrm{~mm} \mathrm{Hg}$.

(3) In patients with tetraplegia, $13(39.4 \%)$ of 33 with AIS A and $6(30 \%)$

of 20 with AIS B documented AD.

(1) AD incidence rate was $36.7 \%$ in suprasacral SCl, $42.6 \%$ above T6 and $15.4 \%$ below $T 6$.

(2) AD was most frequent and severe in cervical injury.

(3) No correlation of BP changes with completeness of injury.

(4) No relationship between BP changes and maximal intravesical pressure, maximal urethral pressure, bladder capacity, detrusor overactivity and urine leakage.

(5) BP increase was more significant in DSD or low bladder compliance.

(1) AD prevalence was $41.7 \%(42 / 101)$.

(2) 21 silent $A D(50 \%)$.

(3) The symptomatic group was significantly younger than the silent group

$\begin{array}{ll}2013,25 & N=101 \text {, above T6 } \\ \text { Taiwan } & \text { (1) urodynamics; } \\ & \text { (2) BP, PR and AD symptoms were recorded before, every } 2 \text { min during } \\ & \text { after the examination. AD was defined as SBP increase of } \geqslant 20 \mathrm{~mm} \mathrm{Hg}\end{array}$

$\begin{array}{ll}2013,25 & N=101 \text {, above T6 } \\ \text { Taiwan } & \text { (1) urodynamics; } \\ & \text { (2) BP, PR and AD symptoms were recorded before, every } 2 \text { min during } \\ & \text { after the examination. AD was defined as SBP increase of } \geqslant 20 \mathrm{~mm} \mathrm{Hg}\end{array}$

$\begin{array}{ll}2013,25 & N=101 \text {, above T6 } \\ \text { Taiwan } & \text { (1) urodynamics; } \\ & \text { (2) BP, PR and AD symptoms were recorded before, every } 2 \text { min during } \\ & \text { after the examination. AD was defined as SBP increase of } \geqslant 20 \mathrm{~mm} \mathrm{Hg}\end{array}$

$\begin{array}{ll}2013,25 & N=101, \text { above T6 } \\ \text { Taiwan } & \text { Intervention: } \\ & \text { (1) urodynamics; } \\ & \text { (2) BP, PR and AD symptoms were recorded before, every } 2 \text { min during and } \\ & \text { after the examination. AD was defined as SBP increase of } \geqslant 20 \mathrm{~mm} \mathrm{Hg} \text {. }\end{array}$

$\begin{array}{ll}2013,25 & N=101 \text {, above T6 } \\ \text { Taiwan } & \text { Intervention: } \\ & \text { (1) urodynamics; } \\ & \text { (2) BP, PR and AD symptoms were recorded before, every } 2 \text { min during } \\ & \text { after the examination. AD was defined as SBP increase of } \geqslant 20 \mathrm{~mm} \mathrm{Hg}\end{array}$

$(40.1 \pm 11.7$ vs $49.1 \pm 10.4$ years $)$

(4) No difference in injury duration, injury level and completeness of injury between the two groups.

(5) Symptomatic group showed more significant DBP increments $(29.5 \pm 9.4$ vs $21.7 \pm 7.9 \mathrm{~mm} \mathrm{Hg})$.

(6) No difference in maximal SBP/DBP, SBP increment, maximal urethral pressure, bladder stiffness and chance of continuous DSD between the two groups.

$\begin{array}{ll}\text { Liu, } & \text { Total sample size: } \\ 2013,34 & N=21 \text {, above T6 with AD } \\ \text { Canada } & \text { Intervention: } \\ & \text { (1) urodynamics; } \\ & \text { (2) Resting BP and HR were recorded before starting the urodynamic } \\ & \text { examination. AD was defined as SBP increase of } \geqslant 20 \mathrm{~mm} \mathrm{Hg.}\end{array}$

(1) SBP increase was more pronounced in individuals with $>2$ years post$\mathrm{SCl}(58.4 \pm 21.0 \mathrm{~mm} \mathrm{Hg})$ than with $<2$ years post-SCl $(38.6 \pm 18.0 \mathrm{~mm}-$ $\mathrm{Hg})(P=0.047)$.

(2) No difference between symptomatic and asymptomatic individuals

$(52.9 \pm 22.1$ vs $51.1 \pm 22.5 \mathrm{~mm} \mathrm{Hg}, P=0.860)$.

(3) No difference between $\mathrm{SCl}$ complete and incomplete individuals

$(54.4+21.5$ vs $46.6+23.0 \mathrm{~mm} \mathrm{Hg}, P=0.454)$.

(4) No correlation ( $r=0.354, P=0.116)$ between maximal detrusor pressure and changes in SBP.

(1) 50 of $90(56 \%)$ individuals developed AD.

$\begin{array}{ll}\text { Sayılır, } & \text { Total sample size: } \\ 2013,26 & N=90 \text { with cervical SCI } \\ \text { Turkey } & \text { Intervention: } \\ & \text { (1) urodynamics; } \\ & \text { (2) AD was defined as SBP }>140 \mathrm{~mm} \mathrm{Hg} \text { or } 20-40 \mathrm{~mm} \mathrm{Hg} \text { increase in adults } \\ & \text { and } 15 \mathrm{~mm} \mathrm{Hg} \text { increase in children. }\end{array}$

Faaborg and $15 \mathrm{~mm} \mathrm{Hg}$ increase in children.

$2014,44 \quad \quad N=8$ with SCI (AIS A) at or above T6

Denmark Intervention:

Intervention:
(1) filling cystometry in comparison with transanal irrigation and digital

evacuation;

(2) No significant difference was found regarding the frequencies of $A D$

between $\mathrm{C} 1-\mathrm{C} 5$ and $\mathrm{C} 6-\mathrm{C} 8$ groups.

(2) AD was defined as an acute rise in SBP of $>30 \mathrm{~mm} \mathrm{Hg}$ above baseline.

(1) SBP increased from $125(106-149) \mathrm{mm} \mathrm{Hg}$ at baseline to 200 (179220) $\mathrm{mm} \mathrm{Hg}$ at maximum stimulation.

(2) SBP increased less during transanal irrigation $(36 \mathrm{~mm} \mathrm{Hg}$, range 30

$63)$ than during digital evacuation $(57 \mathrm{~mm} \mathrm{Hg}$, range $41-75 ; P<0.05)$ or

filling cystometry $(61 \mathrm{~mm} \mathrm{Hg}$, range $55-100 ; P<0.02)$.

(3) Median 'time at risk', defined as SBP $>150 \%$ of baseline, was 4 min (range 2-7) during filling cystometry.

Abbreviations: AD, autonomic dysreflexia; AIS, American Spinal Injury Association Impairment Scale; BP, blood pressure; b.p.m., beats per minute; CMG, cystometrogram; DBP, diastolic BP; DPN, dorsal penile nerve; DSD, detrusor sphincter dyssynergia; ECG, electrocardiogram; HR, heart rate; MAP, mean arterial pressure; MBP, maximal bladder pressure; NDO, neurogenic detrusor overactivity; Pdet, detrusor pressure; PR, pulse rate; SBP, systolic BP; SCI, spinal cord injury; TUS, transurethral sphincterotomy; UDC, uninhibited detrusor contraction.

urodynamics compared with baseline. Linsenmeyer et al. ${ }^{16}$ found urodynamics as an excellent tool in detecting both symptomatic and silent $\mathrm{AD}$ in men with $\mathrm{SCI}$ above T6 who were at an increased risk for AD. Curt et al. ${ }^{17}$ determined urodynamic examination as an effective and standardized diagnostic procedure for provoking signs of AD. In their study, only half of the patients who showed signs of $\mathrm{AD}$ during urodynamic examination presented with clinical symptoms of $\mathrm{AD}$. 
$\mathrm{AD}$ during urodynamics was a result of the bladder distending during the procedure, although symptoms were not always prevalent. The rate of symptomatic $\mathrm{AD}$ in the four relevant studies ${ }^{15-17,25}$ ranged from $50 \%$ to $65 \%$. All individuals involved in these studies were injured at or above T6. Two of the studies ${ }^{16,25}$ compared BP changes and potential factors associated with $\mathrm{AD}$. Linsenmeyer et al. ${ }^{16}$ found that those without symptoms had BP elevations similar to those with symptoms. The SBP before voiding in symptomatic $\mathrm{AD}$ and silent $\mathrm{AD}$ was 114 and $122 \mathrm{~mm} \mathrm{Hg}$, respectively, whereas during voiding SBP was 170 and $167 \mathrm{~mm} \mathrm{Hg}$, respectively. There was no correlation of symptoms with the duration of SCI, maximum voiding pressure or bladder capacity. Huang et al. ${ }^{25}$ demonstrated that SBP in symptomatic $\mathrm{AD}$ increased from $115.5 \pm 16.5$ to $168.4 \pm 32.7 \mathrm{~mm} \mathrm{Hg}$ and from $116.9 \pm 10.3$ to $159.1 \pm 13.9 \mathrm{~mm} \mathrm{Hg}$ in silent $\mathrm{AD}$, whereas $\mathrm{DBP}$ in symptomatic $\mathrm{AD}$ increased from $76.5 \pm 14.4$ to $104.7 \pm 16.3 \mathrm{~mm} \mathrm{Hg}$ and from $76.3 \pm 7.5$ to $98.1 \pm 10.1 \mathrm{~mm} \mathrm{Hg}$ in silent AD. These results were statistically significant for the DBP changes only. In addition, they found that the silent $\mathrm{AD}$ group was significantly older than the symptomatic AD group (49.4 vs 40.1 years, respectively).

According to the diagnostic criteria in ISAFSCI, ${ }^{3,4}$ the primary characteristic of AD includes a minimum SBP increase of $20 \mathrm{~mm} \mathrm{Hg}$ from baseline. Previous studies ${ }^{15-17,24,32,33}$ demonstrated such an increase in BP during urodynamics. Thyberg et al. ${ }^{32}$ found that SBP increased from 20 to $60 \mathrm{~mm} \mathrm{Hg}$ and DBP increased from 15 to 55 $\mathrm{mm} \mathrm{Hg}$ during cystometry. Krum et al. ${ }^{33}$ revealed that SBP and DBP increased significantly in individuals with SCI above T5 with a significant decrease in $\mathrm{HR}$, whereas these cardiovascular parameters did not change significantly in SCI individuals with neurologic lesions below T5 or in a normal control group. Giannantoni et al. ${ }^{15}$ indicated that $\mathrm{BP}$ increase in the $\mathrm{AD}$ group was higher than that in the non- $\mathrm{AD}$ group (SBP $167.5 \pm 24.0 \mathrm{~mm} \mathrm{Hg}$ vs $121.6 \pm 13.4, \quad P<0.01$; DBP $101.8 \pm 8.8 \mathrm{~mm} \mathrm{Hg}$ vs $77.0 \pm 10.3, P<0.01)$. Huang et al. ${ }^{24}$ compared the difference in BP changes between SCI individuals and healthy controls during urodynamic investigation and showed SBP change in individuals with SCI to be significantly higher than in controls $(16.6 \pm 22.5$ vs $9.7 \pm 10.6 \mathrm{~mm} \mathrm{Hg}, P<0.05)$, although these DBP and heart rate changes were not statistically significant.

As previously mentioned, several factors could influence the development of $\mathrm{AD}$, including neurological characteristics (level, completeness and duration of injury), bladder management and neurogenic detrusor overactivity, detrusor sphincter dyssynergia (DSD), bladder compliance and bladder capacity, as found during urodynamic investigation. Among neurological characteristics, neurological level, completeness of SCI and duration of SCI are commonly investigated. Three studies ${ }^{15,21,24}$ demonstrated that $\mathrm{AD}$ was more prevalent in cervical SCI than in thoracic SCI and BP increased more for those with cervical lesions. ${ }^{24}$ However, no significant difference was found regarding the frequencies of $\mathrm{AD}$ between $\mathrm{C} 1-\mathrm{C} 5$ and $\mathrm{C} 6-$ C8 groups. ${ }^{26}$ Giannantoni et al. ${ }^{15}$ found no correlation of $\mathrm{AD}$ to gender, age, disease duration or completeness of SCI. Huang et al. ${ }^{24}$ similarly showed no correlation of BP changes in relation to completeness of injury. Linsenmeyer et al. ${ }^{16}$ found no correlation of $\mathrm{AD}$ with the duration of SCI. However, Liu et al. ${ }^{34}$ revealed that the severity of AD increased with time after SCI, as SBP increases were more pronounced in individuals with $\mathrm{SCI}$ for $>2$ years than in those with $\mathrm{SCI}<2$ years.

Although bladder management is an important issue related to LUT function, Linsenmeyer et al. ${ }^{16}$ reported that there was no correlation between $\mathrm{AD}$ development and various bladder management methods. From urodynamic observation, detrusor function, urethral function and bladder compliance can be obtained, all of which were compared with $\mathrm{AD}$ in several studies. However, inconsistencies existed among studies. Giannantoni et al. ${ }^{15}$ found no difference in incidence of neurogenic detrusor overactivity and DSD, low compliance, uninhibited contraction amplitude and bladder capacity between SCI individuals with and without $\mathrm{AD}$. Schurch et al. ${ }^{35}$ reported that in SCI individuals with UDC the mean arterial pressure increased progressively during bladder contraction until reaching maximal bladder pressure and remained elevated during voiding. Huang et al. ${ }^{24}$ reported no relationship between BP changes and maximal bladder pressure, bladder capacity, neurogenic detrusor overactivity or urine leakage. In the same study, however, BP increase was significantly higher in SCI individuals with both DSD and low bladder compliance than in those without. Perkash ${ }^{36}$ proposed that BP rise could be considered an indicator of DSD and that SBP increases $\geqslant 40 \mathrm{~mm} \mathrm{Hg}$ and DBP increases $\geqslant 20 \mathrm{~mm} \mathrm{Hg}$ were significant enough to suspect DSD in individuals with tetraplegia. Two studies ${ }^{37,38}$ further supported the same relationship between $\mathrm{AD}$ and DSD.

Some studies investigated the methods of mitigation of AD through, for instance, pharmacology therapy, electrical stimulation and surgery. Lindan et al. ${ }^{39}$ used phenoxybenzamine ( $\alpha$-receptor blocker) and nifedipine (calcium channel blocker), whereas Thyberg et al. ${ }^{40}$ used nifedipine only in their study for the prevention of $\mathrm{AD}$. Both studies reported nifedipine as having a prophylactic effect in aborting $\mathrm{AD}$ symptoms. Lindan et al. ${ }^{39}$ also suggested nifedipine as a possibility for the treatment of acute $\mathrm{AD}$, but neither nifedipine nor phenoxybenzamine in regular daily dosage could prevent $\mathrm{AD}$. Lee et al. ${ }^{41}$ performed cystometry with and without dorsal penile nerve stimulation and revealed that dorsal penile nerve stimulation could decrease the $\mathrm{BP}$ elevation in $\mathrm{AD}$ probably by suppressing detrusor contraction. ${ }^{42}$ Several studies ${ }^{37,38,43}$ investigated the BP change after transurethral sphincterotomy, which could further strengthen the relationship between $\mathrm{AD}$ and DSD, which cause bladder distension. Barton et $a{ }^{43}$ found that the frequency and magnitude of $\mathrm{AD}$ could be diminished significantly after transurethral sphincterotomy. Ricottone et al. ${ }^{37}$ reported that 9 out of the 12 individuals experienced cessation of $\mathrm{AD}$ following initial transurethral sphincterotomy, but most required repeat procedures for long-term resolution. Perkash ${ }^{38}$ demonstrated that $\mathrm{BP}$ rises were transitory and not associated with significant symptoms of AD.

In addition, increase in SBP was used to compare the severity of $\mathrm{AD}$ response between urodynamics and cystoscopy, as well as urodynamics and bowel evacuation procedures such as transanal irrigation and digital evacuation. Liu et al. ${ }^{34}$ reported that during cystoscopy SCI individuals developed greater changes in SBP than urodynamics $(67.1 \pm 33.8$ vs $51.8 \pm 21.8 \mathrm{~mm} \mathrm{Hg})$, indicating that stimulation of the urethra/prostate/internal sphincter region probably is a more potent stimulus of $\mathrm{AD}$ than just the filling of the bladder. Faaborg et al. ${ }^{44}$ showed that SBP increased less during transanal irrigation (36 $\mathrm{mm} \mathrm{Hg}$, range 30-63) than during digital evacuation $(57 \mathrm{~mm} \mathrm{Hg}$, range 41-75) or filling cystometry $(61 \mathrm{~mm} \mathrm{Hg}$, range 55-100) - the SBP response between digital evacuation and filling cystometry was insignificant.

Among the described studies, the diagnostic criteria of $\mathrm{AD}$ varied. Most studies ${ }^{17,21,23-25,33,34,41,44}$ used BP changes as the criteria, whereas some studies ${ }^{15,16,39}$ used maximal BP as the criteria. One study $^{26}$ used both of these indicators. In the studies using SBP changes, the criteria varied from 10 to $50 \mathrm{~mm} \mathrm{Hg}$, whereas only three studies $^{24,25,34}$ published after 2009 used $20 \mathrm{~mm} \mathrm{Hg}$ as the criteria, consistent with the ISAFSCI guidelines. Thus the use of the criteria from ISAFSCI should be encouraged in the future to make comparisons between studies easier. 


\section{Cystoscopy and transurethral litholapaxy}

In addition to bladder distension, cystoscopy and transurethral litholapaxy also involve instrumentation into the urethra and bladder. Some studies (Table 3) reported $\mathrm{AD}$ during these procedures. Chancellor et al. ${ }^{45}$ revealed that flexible cystoscopy could decrease the risk of triggering $\mathrm{AD}$. In their study, only 6 of the 39 patients with previous episodes of $\mathrm{AD}$ became hypertensive during cystoscopy. Vespasiani et al. ${ }^{46}$ reported that 3 out of the 17 individuals presented signs and symptoms of $\mathrm{AD}$ during ballistic lithotripter. Liu et al. ${ }^{34}$ reported that the severity of $\mathrm{AD}$ increased with time following SCI, as demonstrated by a more pronounced SBP increase in individuals with SCI for $>2$ years compared with those with SCI for $<2$ years. In addition, no difference in SBP increase was found between symptomatic $\mathrm{AD}$ and asymptomatic $\mathrm{AD}$ individuals, as well as between complete and incomplete individuals during cystoscopy.

Table 3 Cystoscopy and transurethral litholapaxy

First author, Methodology Results
year
(reference),
country

Braddom, Total sample size: $N=7$. Intervention: (1) a single oral dose of mecamyla$1969,{ }^{49}$ USA mine hydrochloride (2.5 mg) before cystometry; (2) BP, HR monitoring.

Alderson, Total sample size: $N=45,24$ cervical SCl. Intervention: (1) transurethral $1976,{ }^{29}$ UK surgery with intravenous induction followed by inhalational anesthesia; (2) $\mathrm{BP}, \mathrm{HR}$ monitoring

Snow, $\quad$ Total sample size: $N=102,57$ above T7. Intervention: (1) cystoscopy; (2) AD $1978,{ }^{30}$ USA was defined as SBP increase $\geqslant 40 \mathrm{~mm} \mathrm{Hg}$

Dykstra, $\quad$ Total sample size: $N=7$, cervical SCI Intervention: (1) cystoscopy; (2) AD 1987,47 USA signs and symptoms monitoring.

Baraka, Total sample size: $N=1$, C6 Intervention: (1) cystoscopy; (2) Meperidine 1989,51 Lebanon Chancellor, Total sample size: $N=69$. Intervention: (1) cystoscopy; (2) AD signs and 1993,45 USA symptoms monitoring.

Vespasiani, Total sample size: $N=17$. Intervention: (1) ballistic lithotripter; (2) AD signs $1996,{ }^{46}$ Italy and symptoms monitoring.

Vaidyanathan, Total sample size: $N=2$, C5 AIS A and C3 AIS A. Intervention: (1) 1996, ${ }^{48}$ UK cystoscopy; (2) BP monitoring.

Yoo, 2008, ${ }^{52}$ Total sample size: $N=28$, complete SCl. Intervention: (1) transurethral Korea litholapaxy; (2) BP, HR monitoring, bispectral index and plasma concentrations of catecholamines and arginine vasopressin.

Yoo, 2011,53 Total sample size: $N=96$, complete. Intervention: (1) transurethral litholaKorea paxy; (2) BP, HR monitoring, bispectral index and plasma concentrations of catecholamines. AD was defined as SBP increase of $>20-40 \mathrm{~mm} \mathrm{Hg}$.

Vaidyanathan, Total sample size: $N=3$, tetraplegia. Intervention: (1) cystoscopy and 2012,50 UK transurethral litholapaxy; (2) AD signs and symptoms monitoring.

Liu, 2013,34 Total sample size: $N=21$, above T6 with AD. Intervention: (1) cystoscopy in Canada
(1) Reduced increase in BP in five out of the seven participants

(2) Reduced or stopped sweating in three of the four participants.

(3) Stopped headache in one participant.

(1) In 21 individuals, SBP rose above preoperative readings. In all, 19 of them had cervical SCI, 1 at T4 and 1 at T6. (2) Maximal rise of SBP was $40 \mathrm{~mm} \mathrm{Hg}$, no case with SBP rise $>160 \mathrm{~mm} \mathrm{Hg}$. (3) Halothane anesthesia was useful in the control of hypertension from $A D$ during transurethral surgery.

(1) 40 (70\%) of the 57 above T7 presented signs and symptoms of AD. No AD was seen below T7. (2) SBP increase ranged between 40 to $120 \mathrm{~mm} \mathrm{Hg}$, HR decrease ranged between 40 to 60 b.p.m. (3) Slow intravenous trimethaphan administration, 10-50 mg for severe hypertension.

(1) Nifedipine $10 \mathrm{mg}$ sublingually, alleviated AD. (2) Nifedipine $10 \mathrm{mg}$ orally, 30 min before cystoscopy, prevented AD..

(1) BP stabilized at $125 / 70-140 / 80 \mathrm{~mm} \mathrm{Hg}$ throughout the surgical proce4 dure. (2) Epidural meperidine prevented AD.

(1) Only 6 of the 39 patients with previous episodes of AD became hypertensive. (2) Flexible cystoscopy causes minimal stimulation leading to the development of AD.

(1) Three individuals presented signs and symptoms of AD.

(1) As cystoscopy was inserted in the urethra, penile erection occurred and BP rose to 200/110 mm Hg, HR decreased to 50 b.p.m. (2) Intravenous salbutamol, in a dose of $10 \mu \mathrm{g}$, produced immediate and persistent penile detumescence and BP decrease.

(1) SBP increased significantly by $67 \pm 33 \mathrm{~mm} \mathrm{Hg}$, whereas HR decreased by $13 \pm 8$ b.p.m. (2) 9 (32\%) SBP $\geqslant 180 \mathrm{~mm} \mathrm{Hg}$ received additional sevoflurane to treat hypertension. (3) The end-tidal concentrations of sevoflurane to prevent AD were EC50 of $3.12 \%$ and EC95 of $3.83 \%$.

(1) $82(85.4 \%)$ of the 96 patients developed AD. (2) The end-tidal concentrations of sevoflurane to prevent AD were reduced to $2.6 \%$ and $2.2 \%$ in the groups receiving 1 and $3 \mathrm{ng} \mathrm{ml}^{-1}$ remifentanil, respectively, in comparison with $3.1 \%(2.9-3.3 \%)$ in the control.

(1) Without anesthesia, BP increased to $>200 / 110 \mathrm{~mm} \mathrm{Hg}$ during cystoscopy. (2) Subarachnoid block prevents occurrence of AD.

(1) SBP increase was more pronounced in individuals with $>2$ years post-SCl $(80.0 \pm 32.2 \mathrm{~mm} \mathrm{Hg})$ than with $<2$ years post-SCl $(41.4 \pm 20.4 \mathrm{~mm} \mathrm{Hg})$ $(P=0.010)$. (2) No difference between symptomatic and asymptomatic individuals $(68.8 \pm 39.6$ vs $65.6 \pm 29.6 \mathrm{~mm} \mathrm{Hg}, P=0.837)$. (3) No difference between $\mathrm{SCl}$ complete and incomplete individuals $(66.4 \pm 31.6$ vs $68.6 \pm 40.7 \mathrm{~mm} \mathrm{Hg}, P=0.895)$. (4) There was statistically more increase $(P=0.039)$ in SBP during cystoscopy $(67.1 \pm 33.8 \mathrm{~mm} \mathrm{Hg})$ in comparison with urodynamics $(51.8 \pm 21.8 \mathrm{~mm} \mathrm{Hg})$. 
The pharmacological management of $\mathrm{AD}$ during cystoscopy has been examined. Dykstra et al. ${ }^{47}$ found nifedipine $10 \mathrm{mg}$ sublingually to be effective in alleviating $\mathrm{AD}$ symptoms, and when administered orally 30 min before cystoscopy, it could prevent $\mathrm{AD}$ altogether. Vaidyanathan et al $^{48}$ found that intravenous salbutamol could produce penile detumescence and BP decrease when the insertion of a cystoscopy into the urethra caused penile erection, BP rise and heart rate decrease. Braddom and Johnson ${ }^{49}$ also reported that a single oral dose $(2.5 \mathrm{mg})$ of mecamylamine (ganglionic blocker) reduced the increase in BP during cystoscopy in five out of the seven participants with SCI. It also was effective in reducing or completely preventing sweating due to $\mathrm{AD}$ in $80 \%$ of participants.

A few studies revealed the relationship of anesthesia and $\mathrm{AD}$ during cystoscopy. Vaidyanathan et al..$^{50}$ reported a BP increase to $>200 / 110 \mathrm{~mm} \mathrm{Hg}$ in tetraplegic individuals without anesthesia. When cystoscopy was conducted again under subarachnoid block, the BP was stable during the procedure, thus demonstrating subarachnoid block as an effective method in preventing the occurrence of $\mathrm{AD}$. Baraka et al. ${ }^{51}$ suggested that epidural meperidine could prevent $\mathrm{AD}$. Alderson et al. ${ }^{29}$ used halothane anesthesia, and although 21 individuals experienced an elevation in SBP, the severity was mild and the maximal SBP change was $40 \mathrm{~mm} \mathrm{Hg}$, with no single elevation reaching levels $>160 \mathrm{mmHg}$. Yoo et al. ${ }^{52}$ reported that SBP increased significantly $(67 \pm 33 \mathrm{~mm} \mathrm{Hg})$ and heart rate decreased (13 \pm 8 b.p. m.) during transurethral litholapaxy. Afterward, they performed their study under general anesthesia in order to avoid AD. They used sevoflurane to prevent $\mathrm{AD}$ and found that the sevoflurane concentration required to block $\mathrm{AD}$ in $50 \%$ of the patients was $3.12 \pm 0.29 \%$. The end-tidal concentrations of sevoflurane for the blockage of $\mathrm{AD}$ in $95 \%$ of the patients by logistic analyses were $3.83 \%$. In another study, ${ }^{53}$ remifentanil was administered with sevoflurane to individuals who developed $\mathrm{AD}$ and demonstrated that concentrations of 1 and $3 \mathrm{ng} \mathrm{ml}^{-1}$ remifentanil would reduce the amount of sevoflurane required to prevent $\mathrm{AD}$ in $\mathrm{SCI}$ patients undergoing transurethral litholapaxy by $16 \%$ and $29 \%$, respectively.

\section{Extracorporeal shock-wave lithotripsy}

ESWL is a noninvasive method for treating patients with renal and urethral calculi, but for individuals with SCI, ESWL is like any other surgical procedure that may cause sufficient stimulation of somatic and/or visceral afferents in the area of the kidney to trigger an $\mathrm{AD}$ response. Several studies (Table 4) have assessed the use of anesthesia in preventing $\mathrm{AD}$ during ESWL. Kabalin et al. ${ }^{54}$ reported that without anesthesia 19 out of the 20 individuals developed AD during ESWL. In another study conducted by Robert et al. ${ }^{55}$ using piezoelectric ESWL, only 3 out of the 11 individuals received sedation and yet no episodes of $\mathrm{AD}$ occurred in any individuals. Stowe et al. ${ }^{31}$ reported that 6 out of the 22 cervical SCI patients with spinal anesthesia developed AD. Spirnak et al. ${ }^{56}$ reported that two out of five tetraplegic individuals developed significant intraoperative hypertension during ESWL. However, a study by Chen et al. ${ }^{57}$ revealed that all individuals had SBP increases $>20 \mathrm{~mm} \mathrm{Hg}$ during ESWL intraoperatively, independent of sedation, spinal anesthesia or no anesthesia. They used trimethaphan, sodium nitroprusside and hydralazine to reduce BP. Burnstein et al. ${ }^{58}$ demonstrated that nifedipine could be given to both acute $\mathrm{AD}$ and before the procedure in order to prevent $\mathrm{AD}$.

\section{Other iatrogenic urological triggers}

In addition to urodynamics, cystoscopy and ESWL, other iatrogenic urological triggers, including voiding cystourethrography, loopography and trial of micturition, have been reported (Table 5). Barbaric et al. ${ }^{59}$ reported two individuals with BP elevation during cystourethrography and loopography, respectively. Vaidyanathan et al. ${ }^{60}$ found that two individuals developed $\mathrm{AD}$ during micturition trial $2-3 \mathrm{~h}$ after the removal of the urethral catheter. In fact, the nature of these triggers is still related to bladder distension. Vaidyanathan et al. ${ }^{60}$ also used nifedipine $10 \mathrm{mg}$ sublingually to treat the $\mathrm{AD}$.

\section{DISCUSSION}

Although $\mathrm{AD}$ has been reported during various urological procedures, there are still issues requiring clarification. The incidence reported by

Table 4 Extracorporeal shock-wave lithotripsy (ESWL)

\begin{tabular}{|c|c|c|}
\hline $\begin{array}{l}\text { First author, year } \\
\text { (reference), country }\end{array}$ & Methodology & Results \\
\hline Spirnak, $1988,{ }^{56}$ USA & $\begin{array}{l}\text { Total sample size: } N=5 \text {, tetraplegia. Intervention: (1) ESWL with } \\
\text { local field block or no anesthesia; (2) AD signs and symptoms } \\
\text { monitoring. }\end{array}$ & $\begin{array}{l}\text { (1) Two developed significant intraoperative hypertension. (2) IV hydralazine } \\
\text { effective in decreasing BP. }\end{array}$ \\
\hline Chen, 1989,57 USA & $\begin{array}{l}\text { Total sample size: } N=9 \text {, tetraplegia. Intervention: (1) ESWL with } \\
\text { IV sedation, spinal anesthesia or no anesthesia; (2) AD signs and } \\
\text { symptoms monitoring. }\end{array}$ & $\begin{array}{l}\text { (1) BP rose from } 106 / 63 \text { to } 171 / 104 \mathrm{~mm} \mathrm{Hg} \text { intraoperatively and } 154 / 103 \\
\text { initially at recovery room. (2) Anesthesia, monitoring and sedation (AMS) with } \\
\text { treatment of hypertensive episodes to be adequate and safe for ESWL. }\end{array}$ \\
\hline Stowe, $1989,{ }^{31}$ USA & $\begin{array}{l}\text { Total sample size: } N=52 \text {, complete, } 28 \text { cervical, } 24 \text { thoracic/ } \\
\text { lumbar. Intervention: (1) ESWL with general or regional } \\
\text { anesthesia; (2) AD signs and symptoms monitoring. }\end{array}$ & $\begin{array}{l}\text { (1) } 9 \text { of } 52 \text { developed AD with BP } 198 \pm 11 / 112 \pm 6 \mathrm{~mm} \mathrm{Hg} \text {. (2) } 6 \text { of } 22 \\
\text { cervical injury patients with spinal anesthesia developed AD. (3) } 3 \text { of } 24 \text { with } \\
\text { thoracic/lumbar injury developed AD. }\end{array}$ \\
\hline $\begin{array}{l}\text { Burnstein, } 1992,58 \\
\text { USA }\end{array}$ & $\begin{array}{l}\text { Total sample size: } N=1 \text {. Intervention: (1) ESWL; (2) AD signs } \\
\text { and symptoms monitoring. }\end{array}$ & $\begin{array}{l}\text { (1) Nifedipine could successfully treat AD. (2) Nifedipine could prophylactically } \\
\text { prevent AD. }\end{array}$ \\
\hline Kabalin, 1993,54 USA & $\begin{array}{l}\text { Total sample size: } N=20 \text {. Intervention: (1) ESWL without } \\
\text { anesthesia; (2) AD signs and symptoms monitoring. }\end{array}$ & $\begin{array}{l}\text { (1) All but } 1 \text { with T12 level experienced AD with SBP increase by } 44 \mathrm{~mm} \mathrm{Hg} \\
\text { and DBP increase by } 24 \mathrm{~mm} \mathrm{Hg}, \mathrm{HR} \text { decrease by } 22 \text { b.p.m. (2) AD was } \\
\text { successfully treated with sublingual nifedipine. }\end{array}$ \\
\hline $\begin{array}{l}\text { Robert, } 1995,55 \\
\text { France }\end{array}$ & $\begin{array}{l}\text { Total sample size: } N=15,8 \text { cervical, } 6 \text { thoracic, } 1 \text { lumbar. } \\
\text { Intervention: (1) Piezoelectric ESWL; (2) AD signs and symptoms } \\
\text { monitoring. }\end{array}$ & (1) No episodes of $A D$ and, in particular, of hypertension during the sessions. \\
\hline
\end{tabular}

Abbreviations: AD, autonomic dysreflexia; BP, blood pressure; b.p.m., beats per minute; DBP, diastolic BP; ESWL, extracorporeal shock-wave lithotripsy; HR, heart rate; IV, intravenous; SBP, systolic BP. 
Table 5 Other iatrogenic urological triggers

\begin{tabular}{|c|c|c|}
\hline $\begin{array}{l}\text { First author, year } \\
\text { (reference), country }\end{array}$ & Methodology & Results \\
\hline Barbaric, 1976,59 USA & $\begin{array}{l}\text { Total sample size: } N=2, C 2 \text { and } C 4 \text {. Intervention: (1) voiding } \\
\text { cystourethrography and loopography; (2) AD signs and symptoms } \\
\text { monitoring. }\end{array}$ & $\begin{array}{l}\text { (1) BP from } 100 / 70 \text { to } 210 / 100 \mathrm{~mm} \mathrm{Hg} \text {, PR changed from } 75 \text { to } 60 \text { b.p.m. } \\
\text { during cystourethrography. (2) BP from } 100 / 70 \text { to } 190 / 100 \mathrm{~mm} \mathrm{Hg} \text {. PR } \\
\text { decreased from } 72 \text { to } 65 \text { b.p.m. during loopography. }\end{array}$ \\
\hline Vaidyanathan, 2003,60 UK & $\begin{array}{l}\text { Total sample size: } N=7 \text {, cervical SCI. Intervention: (1) trial of } \\
\text { micturition; (2) AD signs and symptoms monitoring. }\end{array}$ & $\begin{array}{l}\text { (1) Two developed severe AD. (2) BP rose from } 78 / 48 \text { to } 165 / 80 \mathrm{~mm} \mathrm{Hg} \text { in } \\
\text { one individual after 2-h trail. (3) The maximal BP was } 204 / 80 \mathrm{~mm} \mathrm{Hg} \text { after } \\
2-3 \mathrm{~h} \text { trail, nifedipine } 10 \mathrm{mg} \text { sublingually was given and BP decreased to } \\
137 / 67 \mathrm{~mm} \mathrm{Hg} \text {. }\end{array}$ \\
\hline
\end{tabular}

Abbreviations: $A D$, autonomic dysreflexia; $B P$, blood pressure; b.p.m., beats per minute; $P R$, pulse rate; $S C l$, spinal cord injury.

Huang et al. ${ }^{24}$ as $36.7 \%$ was based on all suprasacral SCI lesions. The majority of AD occurs in SCI individuals injured at or above T6 spinal cord level. If we only calculate the $\mathrm{AD}$ incidence in individuals with SCI at or above T6 in their study, the rate would be $43 \%$, and only $15 \%$ of patients with lesions below T6 developed AD. It is obvious that individuals with higher lesions will have higher incidences of $\mathrm{AD}$. Thus, when all levels of SCI are taken together, a lower overall incidence rate of $\mathrm{AD}$ will be the result. Linsenmeyer et al. ${ }^{16}$ reported the incidence in their study as high as $77.8 \%$, with all patients having complete SCI. Individuals with complete SCI have more frequent and more severe AD. ${ }^{1}$ Thus, if only individuals with complete SCI are included in a study as being representative of the $\mathrm{AD}$ incidence in a subgroup, the rate of $\mathrm{AD}$ would naturally be inflated compared with a group including both complete and incomplete SCI because the AD incidence in individuals with incomplete SCI is lower than that with complete SCI. Therefore, when reporting incidence of $\mathrm{AD}$ during urological procedures, it would be preferable to divide SCI individuals by the levels of their injury in cervical, high thoracic (above T6) and lower (below T6) lesion groups. Furthermore, information on the autonomic completeness of injury should be provided along with the AIS grade in future studies when reporting AD incidence. ${ }^{61}$

According to ISAFSCI, ${ }^{3,4} \mathrm{AD}$ is defined as an SBP change with or without symptoms. Thus symptoms are not necessary components of $\mathrm{AD}$. The rate of symptomatic $\mathrm{AD}$ during urodynamics varied from $50 \%$ to $65 \% .{ }^{15-17,25}$ In addition, the consistency of this rate is higher than that of $\mathrm{AD}$ incidence rates during urodynamics (36.7-77.8\%). However, only two studies ${ }^{16,25}$ have explored the association of factors between symptomatic $\mathrm{AD}$ and silent $\mathrm{AD}$. Linsenmeyer et al. ${ }^{16}$ found that there was no correlation of symptoms of $\mathrm{AD}$ with duration of $\mathrm{SCI}$, whereas Huang et al. ${ }^{25}$ reported that aging decreases $\mathrm{AD}$ symptoms and the magnitude of DBP elevation. Therefore, this area requires further investigation. These data further emphasize the importance and necessity of continuous monitoring of arterial BP as a standard of practice during urodynamics in order to detect and initiate appropriate management for episodes of silent AD.

During urodynamics, several studies ${ }^{15-17,24,32,33}$ have investigated the cardiovascular parameter changes between individuals with and without SCI and between SCI individuals with and without AD. When reporting $\mathrm{BP}$ outcomes, some studies compared baseline $\mathrm{BP}$ and maximal BP, whereas others compared the BP changes. It is recommended to use $\mathrm{BP}$ changes as the primary outcome measure of $\mathrm{AD}$ owing to the fact that normal resting arterial $\mathrm{BP}$ in individuals with cervical and high thoracic SCI is approximately $15-20 \mathrm{~mm} \mathrm{Hg}$ lower than in able-bodied individuals, ${ }^{62}$ and thus elevated BP due to episodes of $\mathrm{AD}$ may not always be obvious.
When comparing factors with potential influence on $\mathrm{AD}$, such as SCI characteristics, LUT function or urodynamic parameters, the data included in the studies vary. As a consequence, it is difficult to compare the results. The purpose of the development of the ISAFSCI is to standardize the data collection and reporting of autonomic function in individuals after SCI. It is therefore recommended to use the items from this standard when collecting data. From the ISAFSCI, the three items that compose LUT function are awareness of the need to empty the bladder (sensation), ability to prevent leakage (continence) and bladder-emptying method. The classification and definition of bladder-emptying methods should be referenced to the International SCI LUT Function Basic Data Set. ${ }^{63}$ The urodynamic parameters established in the ISAFSCI are all derived from the International SCI Urodynamic Basic Data Set, ${ }^{64}$ which includes bladder sensation during filling cystometry, detrusor function, compliance during filing cystometry, urethral function during voiding, detrusor leak point pressure, maximum detrusor pressure, cystometric bladder capacity and postvoid residual volume. In addition to these LUT functions and urodynamic parameters, items pertaining to SCI characteristics are equally important and consist of age, gender, neurological level, completeness and duration of SCI. The latter information is likewise recommended to be reported in a standardized way. ${ }^{65}$ Furthermore, urodynamics or simple cystometry are useful methods to evaluate the effectiveness of interventions used to prevent $\mathrm{AD}$. Of the studies reviewed, the majority were preinterventionpostintervention comparisons or were of limited sample size $(n=8-$ 26). ${ }^{37-41,43,44}$ In an effort to increase evidence-based practice in this area, it is suggested in future studies to perform randomized controlled trials with an appropriate sample size and include cervical/thoracic, complete/incomplete SCI individuals. Although a variety of medications were used in the treatment of hypertension or during a hypertensive crisis, nifedipine in particular was shown to be the most effective during urodynamics, ${ }^{39}$ cystoscopy ${ }^{47}$ and ESWL ${ }^{58}$ both for relief of acute $\mathrm{AD}$ and for the prevention of $\mathrm{AD}$. The assessments of other antihypertensive drugs and their impact on $\mathrm{AD}$ are anticipated for future research.

Flexible cystoscopy is widely accepted as an effective alternative to rigid endoscopy in minimizing occurrence of $\mathrm{AD}$. Rivas et al. ${ }^{66}$ proposed that reduced caliber of the flexible cystoscope would markedly decrease the incidence and severity of $\mathrm{AD}$ during examination when compared with the use of rigid endoscope. Cystoscopy, transurethral litholapaxy and ESWL were considered as surgical procedures; however, the majority of studies related to these procedures focused on the effectiveness of anesthesia on $\mathrm{AD}$ or the consequence of not using anesthesia. Common types of anesthesia used for individuals with SCI include local, subarachnoid, epidural 
and general anesthesia. Topical anesthesia, such as lidocaine $2 \%$ gel, was suggested for routine use during cystoscopy to decrease the afferent impulse, thereby preventing the triggering of an $\mathrm{AD}$ response. ${ }^{66}$ However, other studies have shown that SCI patients undergoing surgical procedures under local anesthesia can still develop AD. Yoo et al. ${ }^{67}$ presented a case involving a tetraplegic male who suffered from left basal ganglia and thalamic hemorrhage associated with $\mathrm{AD}$ during surgery for a pressure sore while under local anesthesia. Cosman et al. found that topical lidocaine was ineffective in limiting or preventing $\mathrm{AD}$ during anorectal procedures, ${ }^{68}$ whereas lidocaine anal block was effective. ${ }^{69}$ The mechanism of subarachnoid block or epidural meperidine in preventing $\mathrm{AD}$ is explained by its ability to block the nociceptive reflexes from the urinary bladder below the level of the neurological lesion. ${ }^{48,49}$ Alderson et al. ${ }^{29}$ reported halothane anesthesia as useful in controlling hypertension from $\mathrm{AD}$ during transurethral surgery. Yoo et al. ${ }^{52,53}$ discovered that sevoflurane was effective in blocking AD during transurethral litholapaxy and that remifentanil could decrease sevoflurane requirements to block $\mathrm{AD}$ in high complete SCI patients. Chen et al. ${ }^{57}$ concluded that anesthesia, monitoring and sedation with treatment of hypertensive episodes as both adequate and safe before ESWL. It has been suggested that 'either sufficient general anesthesia or an adequate level of regional anesthesia' can diminish the deleterious hemodynamic changes of $\mathrm{AD}$, if occurring during ESWL. ${ }^{31}$

Other iatrogenic urological triggers of $\mathrm{AD}$ are mostly related to bladder distension where catheterization is the leading choice for management. ${ }^{59,60}$ If, however, $\mathrm{AD}$ is not managed after catheterization, antihypertensive drugs should be considered. ${ }^{60}$

\section{CONCLUSION}

Among the LUT triggers evoking episodes of $\mathrm{AD}$, iatrogenic factors are common and include urodynamic investigations and cystometry, cystoscopy and transurethral litholapaxy, ESWL and other procedures that may lead to distension of the bladder. $\mathrm{AD}$ was more prevalent in cervical SCI than in thoracic SCI, but the relationship between completeness and $\mathrm{AD}$ remain controversial. Therefore, future studies should report $\mathrm{AD}$ incidence in relation to autonomic completeness of injury. In addition, although preoperative measures (that is, anesthesia) are recommended in some studies, the effectiveness and choice of anesthesia still requires further investigation. Most importantly, BP monitoring should always be performed to detect $\mathrm{AD}$ development during iatrogenic procedures in individuals with SCI. It is suggested that changes in the urodynamic parameters and $\mathrm{AD}$ following $\mathrm{SCI}$ could be determined through urodynamic follow-up. ${ }^{70}$ Upon detection of $\mathrm{AD}$, appropriate management should follow according to the guidelines and protocols recommended in the Consortium for Spinal Cord Medicine guideline. ${ }^{71}$

\section{CONFLICT OF INTEREST}

The authors declare no conflict of interest.

\section{ACKNOWLEDGEMENTS}

Dr Nan Liu is supported by a State scholarship from the China Scholarship Council to the Laboratory of Dr Krassioukov, International Collaboration on Research Discoveries (ICORD), University of British Columbia, Canada; and Dr Andrei Krassioukov is supported by grants from the Canadian Institute of Health Research, Canadian Heart and Stroke Foundation and Craig Neilsen Foundation.
1 Krassioukov A, Warburton DE, Teasell R, Eng JJ. A systematic review of the management of autonomic dysreflexia after spinal cord injury. Arch Phys Med Rehabil 2009; 90: 682-695.

2 Teasell RW, Arnold JM, Krassioukov A, Delaney GA. Cardiovascular consequences of loss of supraspinal control of the sympathetic nervous system after spinal cord injury. Arch Phys Med Rehabil 2000; 81: 506-516.

3 Alexander MS, Biering-Sorensen F, Bodner D, Brackett NL, Cardenas D, Charlifue S et al. International standards to document remaining autonomic function after spinal cord injury. Spinal Cord 2009; 47: 36-43.

4 Krassioukov A, Biering-Sørensen F, Donovan W, Kennelly M, Kirshblum S, Krogh K et al. International standards to document remaining autonomic function after spinal cord injury. J Spinal Cord Med 2012; 35: 201-210.

5 Yarkony GM, Katz RT, Wu YC. Seizures secondary to autonomic dysreflexia. Arch Phys Med Rehabil 1986; 67: 834-835.

6 Pine ZM, Miller SD, Alonso JA. Atrial fibrillation associated with autonomic dysreflexia. Am J Phys Med Rehabil 1991; 70: 271-273

7 Valles M, Benito J, Portell E, Vidal J. Cerebral hemorrhage due to autonomic dysreflexia in a spinal cord injury patient. Spinal Cord 2005; 43: 738-740.

8 Ho CP, Krassioukov AV. Autonomic dysreflexia and myocardial ischemia. Spinal Cord 2010; 48: 714-715.

9 Eltorai I, Kim R, Vulpe M, Kasravi H, Ho W. Fatal cerebral hemorrhage due to autonomic dysreflexia in a tetraplegic patient: case report and review. Paraplegia 1992; 30: 355-360.

10 Dolinak D, Balraj E. Autonomic dysreflexia and sudden death in people with traumatic spinal cord injury. Am J Forensic Med Pathol 2007; 28: 95-98.

11 Wan D, Krassioukov AV. Life-threatening outcomes associated with autonomic dysreflexia: a clinical review. J Spinal Cord Med 2014; 37: 2-10.

12 Karlsson AK. Autonomic dysreflexia. Spinal Cord 1999; 37: 383-391.

13 Kewalramani LS. Autonomic dysreflexia in traumatic myelopathy. Am J Phys Med 1980; 59: 1-21.

14 Calder KB, Estores IM, Krassioukov A. Autonomic dysreflexia and associated acute neurogenic pulmonary edema in a patient with spinal cord injury: a case report and review of the literature. Spinal Cord 2009; 47: 423-425.

15 Giannantoni A, Di Stasi SM, Scivoletto G, Mollo T, Silecchia A, Fuoco U et al. Autonomic dysreflexia during urodynamics. Spinal Cord 1998; 36: 756-760.

16 Linsenmeyer TA, Campagnolo DI, Chou IH. Silent autonomic dysreflexia during voiding in men with spinal cord injuries. J Urol 1996; 155: 519-522.

17 Curt A, Nitsche B, Rodic B, Schurch B, Dietz V. Assessment of autonomic dysreflexia in patients with spinal cord injury. J Neurol Neurosurg Psychiatry 1997; 62: 473-477.

18 Kirshblum SC, House JG, O'connor KC. Silent autonomic dysreflexia during a routine bowel program in persons with traumatic spinal cord injury: a preliminary study. Arch Phys Med Rehabil 2002; 83: 1774-1776.

19 Ekland MB, Krassioukov AV, McBride KE, Elliott SL. Incidence of autonomic dysreflexia and silent autonomic dysreflexia in men with spinal cord injury undergoing sperm retrieval: implications for clinical practice. J Spinal Cord Med 2008; 31: 33-39.

20 Blackmer J. Rehabilitation medicine: 1. Autonomic dysreflexia. CMAJ 2003; 169: 931-935.

21 Lindan R, Joiner E, Freehafer AA, Hazel C. Incidence and clinical features of autonomic dysreflexia in patients with spinal cord injury. Paraplegia 1980; 18: 285-292.

22 Courtois F, Rodrigue X, Côté I, Boulet M, Vézina JG, Charvier K et al. Sexual function and autonomic dysreflexia in men with spinal cord injuries: how should we treat? Spinal Cord 2012; 50: 869-877.

23 Chancellor MB, Lavelle J, Ozawa H, Jung SY, Watanabe T, Kumon H. Ice-water test in the urodynamic evaluation of spinal cord injured patients. Tech Urol 1998; 4: 87-91.

24 Huang YH, Bih LI, Chen GD, Lin CC, Chen SL, Chen WW. Autonomic dysreflexia during urodynamic examinations in patients with suprasacral spinal cord injury. Arch Phys Med Rehabil 2011; 92: 1450-1454

25 Huang YH, Bih LI, Liao JM, Chen SL, Chou LW, Lin PH. Blood pressure and age associated with silent autonomic dysreflexia during urodynamic examinations in patients with spinal cord injury. Spinal Cord 2013; 51: 401-405.

26 Sayılır S, Ersöz M, Yalçın S. Comparison of urodynamic findings in patients with upper and lower cervical spinal cord injury. Spinal Cord 2013; 51: 780-783.

27 Rapidi CA, Petropoulou K, Galata A, Fragkaki M, Kandylakis E, Venieri M. Neuropathic bladder dysfunction in patients with motor complete and sensory incomplete spinal cord lesion. Spinal Cord 2008; 46: 673-678.

28 West CR, Wong SC, Krassioukov AV. Autonomic cardiovascular control in Paralympic athletes with spinal cord injury. Med Sci Sports Exerc 2014; 46: 60-68.

29 Alderson JD, Thomas DG. The use of halothane anesthesia to control autonomic hyperreflexia during trans-urethral surgery in spinal cord injury patients. Paraplegia 1975; 13: 183-190.

30 Snow JC, Sideropoulos HP, Kripke BJ, Freed MM, Shah NK, Schlesinger RM. Autonomic hyperreflexia during cystoscopy in patients with high spinal cord injuries. Paraplegia 1978; 15: 327-332.

31 Stowe DF, Bernstein JS, Madsen KE, McDonald DJ, Ebert TJ. Autonomic hyperreflexia in spinal cord injured patients during extracorporeal shock wave lithotripsy. Anesth Analg 1989; 68: 788-791.

32 Thyberg M, Ertzgaard P, Gylling M, Granérus G. Blood pressure response to detrusor pressure elevation in patients with a reflex urinary bladder after a cervical or high thoracic spinal cord injury. Scand J Rehabil Med 1992; 24: 187-193.

33 Krum H, Louis WJ, Brown DJ, Clarke SJ, Fleming JA, Howes LG. Cardiovascular and vasoactive hormone responses to bladder distension in spinal and normal man. Paraplegia 1992; 30: 348-354. 
34 Liu N, Fougere R, Zhou MW, Nigro MK, Krassioukov AV. Autonomic dysreflexia severity during urodynamics and cystoscopy in individuals with spinal cord injury. Spinal Cord 2013; 51: 863-867.

35 Schurch B, Knapp PA, Rossier AB. Autonomic hyperreflexia revisited. Urol Int 1997; 58: 148-152.

36 Perkash I. Pressor response during cystomanometry in spinal injury patients complicated with detrusor-sphincter dyssynergia. J Urol 1979; 121: 778-782.

37 Ricottone AR, Pranikoff K, Steinmetz JR, Constantino G. Long-term follow-up of sphincterotomy in the treatment of autonomic dysreflexia. Neurourol Urodyn 1995; 14: 43-46.

38 Perkash I. Autonomic dysreflexia and detrusor-sphincter dyssynergia in spinal cord injury patients. J Spinal Cord Med 1997; 20: 365-370.

39 Lindan R, Leffler EJ, Kedia KR. A comparison of the efficacy of an alpha-I-adrenergic blocker in the slow calcium channel blocker in the control of autonomic dysreflexia. Paraplegia 1985; 23: 34-38.

40 Thyberg M, Ertzgaard P, Gylling M, Granerus G. Effect of nifedipine on cystometryinduced elevation of blood pressure in patients with a reflex urinary bladder after a high level spinal cord injury. Paraplegia 1994; 32: 308-313.

41 Lee YH, Creasey GH, Lim H, Song J, Song K, Kim J. Detrusor and blood pressure responses to dorsal penile nerve stimulation during hyperreflexic contraction of the bladder in patients with cervical cord injury. Arch Phys Med Rehabil 2003; 84: $136-140$.

42 Hansen J, Media S, Nøhr M, Biering-Sørensen F, Sinkjær T, Rijkhoff NJM. Treatment of neurogenic detrusor overactivity in spinal cord injured patients by conditional electrical stimulation. J Urol 2005; 173: 2035-2039.

43 Barton CH, Khonsari F, Vaziri ND, Byrne C, Gordon S, Friis R. The effect of modified transurethral sphincterotomy on autonomic dysreflexia. J Urol 1986; 135: 83-85.

44 Faaborg PM, Christensen P, Krassioukov A, Laurberg S, Frandsen E, Krogh K. Autonomic dysreflexia during bowel evacuation procedures and bladder filling in subjects with spinal cord injury. Spinal Cord 2014; 52: 494-498.

45 Chancellor MB, Rivas DA, Erhard MJ, Hirsch IH, Bagley DH. Flexible cystoscopy during urodynamic evaluation of spinal cord-injured patients. J Endourol 1993; 7: 531-535.

46 Vespasiani G, Pesce F, Finazzi Agró E, Virgili G, Giannantoni A, Micali S et al. Endoscopic ballistic lithotripsy in the treatment of bladder calculi in patients with neurogenic voiding dysfunction. J Endourol 1996; 10: 551-554.

47 Dykstra DD, Sidi AA, Anderson LC. The effect of nifedipine on cystoscopy-induced autonomic hyperreflexia in patients with high spinal cord injuries. J Urol 1987; 138 1155-1157.

48 Vaidyanathan S, Watt JW, Soni BM, Krishnan KR. Intravenous salbutamol treatment for penile erection arising during cystoscopy of cervical spinal cord injury patients. Spinal Cord 1996; 34: 691-695.

49 Braddom RL, Johnson EW. Mecamylamine in control of hyperreflexia. Arch Phys Med Rehabil 1969; 50: 448-453.

50 Vaidyanathan S, Soni B, Selmi F, Singh G, Esanu C, Hughes P et al. Are urological procedures in tetraplegic patients safely performed without anesthesia? a report of three cases. Patient Saf Surg 2012; 6: 3.

51 Baraka A, Noueihid R, Sibai AN, Baroody M, Louis F, Hemady K. Epidural meperidine for control of autonomic hyperreflexia in a quadriplegic undergoing cystoscopy. Middle East J Anesthesiol 1989; 10: 185-188.

52 Yoo KY, Jeong CW, Kim SJ, Chung ST, Bae HB, Oh KJ et al. Sevoflurane concentrations required to block autonomic hyperreflexia during transurethral litholapaxy in patients with complete spinal cord injury. Anesthesiology 2008; 108: 858-863.

53 Yoo KY, Jeong CW, Kim SJ, Jeong ST, Kim WM, Lee HK et al. Remifentanil decreases sevoflurane requirements to block autonomic hyperreflexia during transurethra litholapaxy in patients with high complete spinal cord injury. Anesth Analg 2011; 112: 191-197.

54 Kabalin JN, Lennon S, Gill HS, Wolfe V, Perkash I. Incidence and management of autonomic dysreflexia and other intraoperative problems encountered in spinal cord injury patients undergoing extracorporeal shock wave lithotripsy without anesthesia on a second generation lithotriptor. J Urol 1993; 149: 1064-1067.

55 Robert M, Bennani A, Ohanna F, Guiter J, Avérous M, Grasset D. The management of upper urinary tract calculi by piezoelectric extracorporeal shock wave lithotripsy in spinal cord injury patients. Paraplegia 1995; 33: 132-135.

56 Spirnak JP, Bodner D, Udayashankar S, Resnick MI. Extracorporeal shock wave lithotripsy in traumatic quadriplegic patients: can it be safely performed without anesthesia?J Urol 1988; 139: 18-19.

57 Chen L, Castro AD. Autonomic hyperreflexia during extracorporeal shock-wave lithotripsy (ESWL) in quadriplegic patients. Can J Anaesth 1989; 36: 604-605.

58 Burnstein A, Richlin D, Sotolongo JR Jr. Nifedipine pretreatment for prevention of autonomic hyperreflexia during anesthesia-free extracorporeal shock wave lithotripsy. J Urol 1992; 147: 676-677.

59 Barbaric ZL. Autonomic dysreflexia in patients with spinal cord lesions: complication of voiding cystourethrography and Ileal loopography. AJR Am J Roentgenol 1976; 127: 293-295.

60 Vaidyanathan S, Soni BM, Sett P, Singh G, Oo T, Hughes PL et al. Flawed trial of micturition in cervical spinal cord injury patients: guidelines for trial of voiding in men with tetraplegia. Spinal Cord 2003; 41: 667-672.

61 Kirshblum SC, Burns SP, Biering-Sorensen F, Donovan W, Graves DE, Jha A et al. International standards for neurological classification of spinal cord injury (revised 2011). J Spinal Cord Med 2011; 34: 535-546.

62 Claydon VE, Elliott SL, Sheel AW, Krassioukov A. Cardiovascular responses to vibrostimulation for sperm retrieval in men with spinal cord injury. J Spinal Cord Med 2006; 29: 207-216

63 Biering-Sørensen F, Craggs M, Kennelly M, Schick E, Wyndaele JJ. International lower urinary tract function basic spinal cord injury data set. Spinal Cord 2008; 46: 325-330.

64 Biering-Sørensen F, Craggs M, Kennelly M, Schick E, Wyndaele JJ. International urodynamic basic spinal cord injury data set. Spinal Cord 2008; 46: 513-516.

65 DeVivo MJ, Biering-Sørensen F, New P, Chen Y. Standardization of data analysis and reporting of results from the International Spinal Cord Injury Core Data Set. Spinal Cord 2011; 49: 596-599.

66 Rivas DA, Chancellor MB. Flexible cystoshypecopy in spinal cord injury. Review article. Paraplegia 1994; 32: 454-462.

67 Yoo KY, Jeong CW, Kim WM, Lee HK, Kim SJ, Jeong ST et al. Fatal cerebral haemorrhage associated with autonomic hyperreflexia during surgery in the prone position in a quadriplegic patient: a case report. Minerva Anestesiol 2010; 76 : 554-558.

68 Cosman BC, Vu TT, Plowman BK. Topical lidocaine does not limit autonomic dysreflexia during anorectal procedures in spinal cord injury: a prospective, double-blind study. Int J Colorectal Dis 2002; 17: 104-108.

69 Cosman BC, Vu TT. Lidocaine anal block limits autonomic dysreflexia during anorectal procedures in spinal cord injury: a randomized, double-blind, placebo-controlled trial. Dis Colon Rectum 2005; 48: 1556-1561.

70 Linsenmeyer TA, Linsenmeyer MA. Impact of annual urodynamic evaluations on guiding bladder management in individuals with spinal cord injuries. J Spinal Cord Med 2013; 36: 420-426.

71 Consortium for Spinal Cord Medicine. Acute management of autonomic dysreflexia: individuals with spinal cord injury presenting to health-care facilities. J Spinal Cord Med 2002; 25: S67-S88. 